\title{
Rituximab Maintenance for the Treatment of Patients With Follicular Lymphoma: An Updated Systematic Review and Meta- analysis of Randomized Trials
}

\author{
Liat Vidal, Anat Gafter-Gvili, Gilles Salles, Martin H. Dreyling, \\ Michele Ghielmini, Shu-Fang Hsu Schmitz, Ruth Pettengell, \\ Mathias Witzens-Harig, Ofer Shpilberg \\ Manuscript received February 10, 2011; revised September 18, 2011; accepted \\ September 20, 2011
}

Correspondence to: Liat Vidal, MD, MSc, Institute of Hematology, Davidoff Cancer Center, Beilinson Hospital, Rabin Medical Center, Petah-Tikva 49100, Israel (e-mail: vidallit@yahoo.com).

In a previous systematic review and meta-analysis of five randomized controlled trials comparing rituximab maintenance with no maintenance (observation or rituximab at progression) for patients with follicular lymphoma, we reported that rituximab maintenance treatment improved the overall survival of patients. In this study, we did a similar search of the electronic databases updated through December 31, 2010, and included nine trials and 2586 follicular lymphoma patients. Hazard ratios (HRs) for time-to-event data were estimated and pooled using the inverse variance method. Risk ratios for dichotomous data were pooled using a fixed effect model. Patients treated with rituximab maintenance had improved overall survival (pooled HR of death $=0.76,95 \%$ confidence interval $[\mathrm{Cl}]=0.62$ to 0.92) compared with patients in the no maintenance group. Patients with refractory or relapsed (ie, previously treated) follicular lymphoma treated with rituximab maintenance had improved overall survival (pooled $\mathrm{HR}$ of death $=0.72,95 \% \mathrm{Cl}=0.57$ to $\mathbf{0 . 9 1}$ ), whereas previously untreated patients had no survival benefit (pooled HR of death $=0.86,95 \% \mathrm{Cl}=0.60$ to 1.25 ). The rate of infection-related adverse events was higher in the rituximab maintenance group (pooled risk ratio $=1.67,95 \% \mathrm{Cl}=1.40$ to 2.00). These results further support the use of rituximab maintenance in the standard of care for refractory or relapsed follicular lymphoma.

J Natl Cancer Inst 2011;103:1799-1806

Follicular lymphoma is a "slow growing" B-cell lymphoma. The median age at diagnosis is 63 years (1). Most patients are diagnosed with advanced stage (Ann Arbor stage III or IV) (2) and are followed without chemotherapy until fever, weight loss or night sweats (B symptoms), or signs of high tumor bulk occur, or the lymphoma jeopardizes an organ function (known as the Groupe d'Etude des Lymphomes Folliculaires [GELF] criteria) $(3,4)$. Patients respond well to the initial (firstline) rituximab-chemotherapy induction but typically experience repeated relapses and shortening of the time from treatment to treatment (4). Survival of patients with follicular lymphoma is shorter compared with a matched cohort from the general population, with a median survival of approximately 10 years (95\% confidence interval $[\mathrm{CI}]=8$ to 12 years $)(1,5)$.

Addition of rituximab to induction chemotherapy (rituximab-chemotherapy induction) improves survival of patients with follicular lymphoma compared with induction chemotherapy, but most patients are not cured and experience relapse after a median of 4 years $(95 \% \mathrm{CI}=3.17$ to not reached) (6-8). Rituximab maintenance treatment after any induction therapy improves progression-free survival, but evidence of improved overall survival is lacking from randomized controlled trials $(9,10)$. To evaluate the effect of rituximab maintenance treatment on the overall survival of patients with follicular lymphoma, previously we performed a systematic review and meta-analysis (11) of five randomized controlled trials conducted between the years 1998 and 2004 in which 985 follicular lymphoma patients were randomly assigned to rituximab maintenance treatment or to no maintenance (observation or rituximab at progression). Induction therapy consisted of rituximab or chemotherapy or a combination of rituximab and chemotherapy. Results demonstrated a statistically significant survival benefit for patients with refractory or relapsed (ie, previously treated) follicular lymphoma who received rituximab maintenance treatment (pooled hazard ratio [HR] of death $=$ $0.58,95 \% \mathrm{CI}=0.42$ to 0.79 ) but not for patients after first-line induction therapy (pooled HR of death $=0.68,95 \% \mathrm{CI}=0.37$ to 1.25$)$. Since our previous publication (11), the trials included in the systematic review and meta-analysis have published updated results, and in addition, new clinical trials have been completed. In this study, we report an updated systematic review and meta-analysis integrating these new results.

The Cochrane Collaboration policy requires all systematic reviews to be updated within 2 years (12). Because the literature search for this review was done in June 2007, we decided to update it in December 2010. A search for randomized controlled trials was performed as described previously (11). We searched The Cochrane Central Register of Controlled Trials, published in The Cochrane Library (issue 4, 2010); PubMed (1966 to December 2010); EMBASE (1974 to June 2007); LILACS (1982 to December 2010); the database of clinical trials in hematologic malignancies (www.hematology-studies. org); Conference Proceedings of the American Society of Hematology (1995 to 2010), Conference Proceedings of the American Society of Clinical Oncology Annual Meeting (1995 to 2010), and Proceedings of the European Hematology Association; and databases of ongoing and unpublished trials (http://www.controlledtrials.com/, http://www.clinicaltrials.gov/ ct, http://clinicaltrials.nci.nih.gov/). The 


\section{CONTEXTS AND CAVEATS}

\section{Prior knowledge}

Most follicular lymphoma patients respond to induction chemotherapy but experience repeated relapses. A previously conducted systematic review and meta-analysis of five randomized controlled trials that compared rituximab maintenance treatment with no maintenance showed survival benefit for patients with refractory or relapsed (previously treated) follicular lymphoma who received rituximab maintenance, but not untreated patients.

\section{Study design}

An updated systematic review and metaanalysis was conducted by including nine randomized trials, and patients treated with rituximab maintenance were compared with no maintenance group.

\section{Contribution}

Patients treated with rituximab maintenance showed statistically significantly better overall and progression-free survival compared with patients in the no maintenance group. Subgroup analysis of overall survival showed that patients with refractory or relapsed follicular lymphoma had a clear survival benefit with rituximab maintenance treatment, but previously untreated patients did not have a statistically significant survival benefit. A higher rate of infection-related adverse events was noted in the rituximab maintenance group.

\section{Implications}

The updated meta-analysis confirms the results of the former meta-analysis. Rituximab maintenance improves survival in previously treated patients, and although untreated patients show progression-free survival benefit, they do not show overall survival benefit. The higher rate of infectionrelated adverse events in the rituximab maintenance group needs to be considered while treating the patients.

\section{Limitations}

An increased chance of false-positive results is possible because of repeated meta-analysis.

\section{From the Editors}

terms "follicular" or "indolent" and similar terms, and "lymphoma" and similar terms were cross-searched with "rituximab" or "monoclonal antibodies" and similar terms. We contacted the first or corresponding author of each included trial to obtain complementary information or information on unpublished trials. The primary outcome was overall survival. Secondary outcomes included progression-free survival [as defined in Cheson et al. (13)], quality of life, and adverse events: grade 3 or 4 adverse events ([according to the US National Cancer Institute's Common Terminology Criteria for Adverse Events, CTCAE, version 3]. If the trials used the term grade but did not define the grading system, we assumed grading was defined according to CTCAE), adverse events requiring discontinuation of therapy, infections, and severe infections (as defined in each trial). In our previous protocol designed in 2007 , we also planned to analyze event-free survival, rate of disappearance of B-cell CLL/lymphoma 2 (BCL2) protein from biopsy specimen, and response duration. We amended the protocol and did not include these outcome measures in the current meta-analysis.

Subgroup analyses for the primary outcome were planned according to the type of induction therapy (chemotherapy only, rituximab only, rituximab combined with chemotherapy, any regimen containing rituximab), rituximab schedule, treatment line, blinding of patients, caregivers, or outcome assessors, and adequacy of allocation concealment and adequacy of sequence generation. All subgroup analyses of progression-free survival (by type of induction therapy, type of chemotherapy, treatment line) were not planned a priori in the protocol.

Hazard ratios and $95 \%$ confidence intervals for time-to-event outcomes were estimated $(14,15)$ and pooled using inverse variance method in a fixed effect model. A hazard ratio less than 1.0 was in favor of rituximab maintenance treatment. Risk ratios (RRs) and 95\% confidence intervals for dichotomous data were estimated and pooled using a fixed effect model (the Mantel-Haenszel method) (16). For the primary outcome, we performed a sensitivity analysis by repeating the analysis using a random effects model [the DerSimonian and Laird method; (17)]. We assessed heterogeneity of trial results by the $\chi^{2}$ test of heterogeneity and the $I^{2}$ statistic of inconsistency. Statistically significant heterogeneity was defined as $P$ less than .1 or an $I^{2}$ statistic greater than $50 \%$ (18). All statistical tests were done by Review Manager (RevMan) version 5.1 (Copenhagen: The Nordic Cochrane Centre, The Cochrane Collaboration, 2011) and were two-sided.

The literature search identified 873 references, of which 64 references were considered potentially relevant (8-10,19-79), and 50 references were excluded (19-68). Ten trials fulfilled inclusion criteria (810,69-79), including five new trials $(8,69,73,76-78)$ and three updated data of trials $(71,72,75)$ included in our previous report (11). One trial did not report relevant clinical data (78). Two of the publications $(71,79)$ reported the outcomes of different subsets of patients from the same trial.

The trial and patient characteristics are shown in Tables 1 and 2. Patients were eligible for trial entry if they had at least partial response $(8,10,73-76)$ or at least stable disease $(9,69-72,79)$ after induction therapy. In one trial (70), patients in the no maintenance group were eligible for rituximab upon progression of follicular lymphoma; in other trials, patients in the control group were observed without rituximab treatment.

Patients included in one trial (69) fulfilled GELF criteria for deferred treatment (3). In the original trial (69), patients were randomly assigned to one of three groupsobservation, rituximab induction, or rituximab induction and maintenance. To avoid overestimation of the effect of rituximab maintenance, we chose to compare patients who received rituximab induction and maintenance with those who received rituximab induction only and not with those in the observation group. Thus, in this meta-analysis, patients who received only rituximab induction and no maintenance were used as the control group.

Nine trials performed between 1998 and 2009 (2586 patients) were eligible for the meta-analysis of overall survival (810,69-77,79). Patients treated with rituximab maintenance had statistically significantly better overall survival compared with patients in the no maintenance group (pooled HR of death $=0.76,95 \%$ $\mathrm{CI}=0.62$ to 0.92$)$ (Figure 1$)$. No statistically significant heterogeneity among the trials was observed for overall survival $\left(P_{\text {heterogeneity }}=.0\right)$. The funnel plot of the pri- 


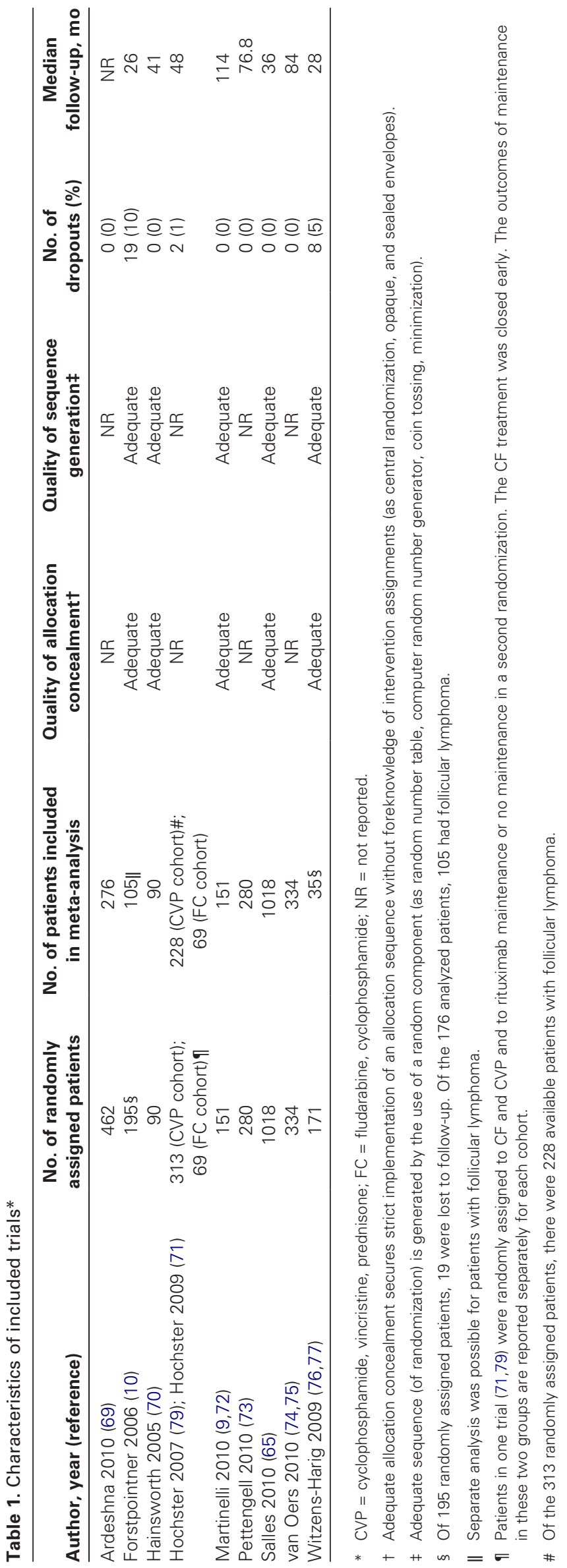

mary outcome did not support a publication bias (data not shown).

A subgroup analysis of overall survival showed that patients with refractory or relapsed (ie, previously treated) follicular lymphoma (909 patients) $(9,10,70,72-75)$ had a clear survival benefit with rituximab maintenance treatment (pooled HR of death $=0.72,95 \% \mathrm{CI}=0.57$ to 0.91 ), whereas previously untreated patients (maintenance after first-line induction therapy) (1650 patients) $(8,9,69,71,72,79)$ did not (pooled HR of death $=0.86,95 \%$ $\mathrm{CI}=0.60$ to 1.25 ) (Figure 1 , and Supplementary Table 1, available online). Chemotherapy regimen and the schedule of rituximab maintenance had no statistically significant effect on outcome (Supplementary Table 1, available online). Three trials included patients whose induction therapy consisted of single-agent rituximab with no chemotherapy $(9,69,70,72)$. Analysis of these trials (516 patients) showed that rituximab maintenance treatment had no statistically significant effect on overall survival compared with no maintenance therapy (pooled HR of death $=0.76,95 \% \mathrm{CI}=0.53$ to 1.01 ). The sensitivity analysis by quality of allocation concealment (adequate or not reported) did not show an effect of quality of concealment on the outcomes (Supplementary Table 1, available online).

In most of the included trials, progressionfree survival improved with rituximab maintenance treatment compared with no maintenance (8-10,69-76). The pooled hazard ratios from nine trials (2550 patients) $(8,10,69-73,75,76,79)$ showed a statistically significantly improved progression-free survival (pooled HR of disease progression or death $=0.54,95 \% \mathrm{CI}=0.48$ to 0.60 ). This effect was consistent both in previously untreated patients (1650 patients) $(8-10,69,71,79)$ (pooled HR of disease progression or death $=0.52,95 \% \mathrm{CI}=0.44$ to 0.61 ) and in those with refractory or relapsed lymphoma (maintenance rituximab after two or more inductions) (909 patients) $(9,10,70,72,73,75)$ (pooled HR of disease progression or death $=0.60,95 \%$ $\mathrm{CI}=0.49$ to 0.72 ), following different induction therapies: rituximab alone (516 patients) $(9,69,70,72)$ (pooled HR of disease progression or death $=0.50,95 \% \mathrm{CI}=0.39$ to 0.65 ); chemotherapy alone (297 patients) $(71,79)$ (pooled HR of disease progression 


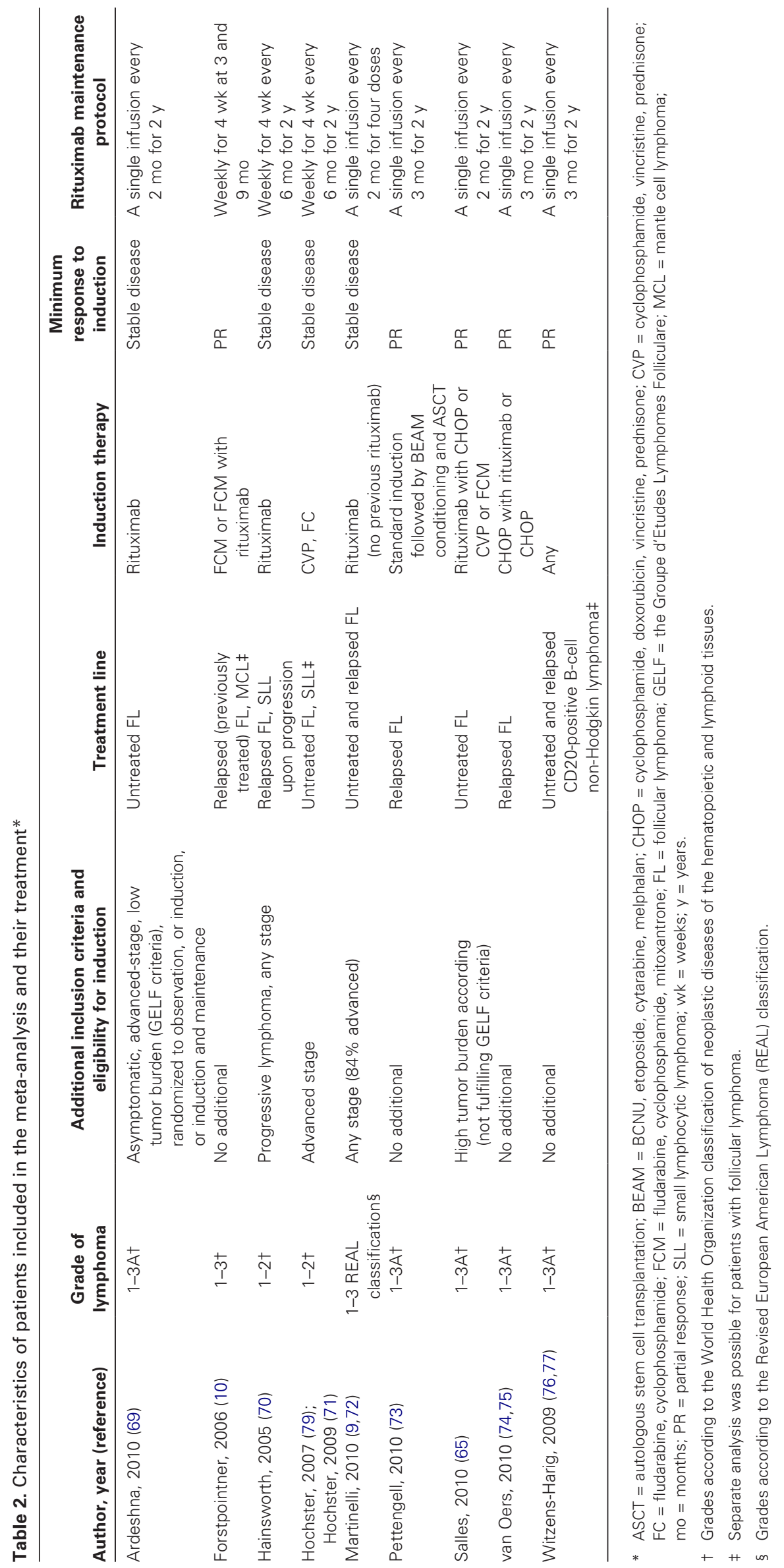

or death $=0.49,95 \% \mathrm{CI}=0.37$ to 0.66 ); and rituximab-chemotherapy (1352 patients) $(8,74,75)$ (pooled HR of disease progression or death $=0.58$, $95 \% \mathrm{CI}=0.48$ to 0.70 ). The benefit in progression-free survival was observed in patients treated with different chemotherapy regimens (with or without rituximab); in patients treated with cyclophosphamide, vincristine, adriamycin, and prednisone, the pooled hazard ratio for disease progression or death was $0.53(95 \% \mathrm{CI}=0.44$ to 0.64 ), with cyclophosphamide, vincristine, and prednisone the pooled hazard ratio of disease progression or death was 0.50 ( $95 \% \mathrm{CI}=0.38$ to 0.66 ), with fludarabinecontaining regimen the hazard ratio of disease progression or death was 0.58 (95\% $\mathrm{CI}=0.40$ to 0.84 ).

In two trials, the quality of life was assessed and censored at the time of progression $(8,77)$. As shown in each of these trials, rituximab maintenance did not impair the quality of life. We could not analyze quality of life in the meta-analysis because of the scarcity of data.

Rituximab maintenance treatment was associated with a higher rate of grade 3 or 4 adverse events compared with the no maintenance (1598 patients) $(8-10,69)(\mathrm{RR}=$ $1.60,95 \% \mathrm{CI}=1.29$ to 1.99$)$. Rituximab maintenance group was also associated with a higher rate of infections compared with no maintenance (1656 patients) (8$10,74,75)$ (pooled $\mathrm{RR}=1.67,95 \% \mathrm{CI}=$ 1.40 to 2.00 ). When only grade 3 or 4 infection-related adverse events were included in the analysis (1656 patients) $(8,10,72,74,75)$, rituximab maintenance was associated with an even higher rate compared with no maintenance (pooled $\mathrm{RR}=$ $3.55,95 \% \mathrm{CI}=1.88$ to 6.69 ). A higher rate of adverse events requiring discontinuation of rituximab (1433 patients) $(8,70,74)$ was associated with rituximab maintenance group compared with no maintenance group (pooled $\mathrm{RR}=2.72,95 \% \mathrm{CI}=1.30$ to 5.68).

Rituximab maintenance improved overall survival and disease control in patients with follicular lymphoma who responded to induction therapy $(P=.006)$. The accumulating data from new and updated clinical trials strengthen the results of our former meta-analysis (11). The large sample size and longer follow-up period in some of the trials consolidate the results of 


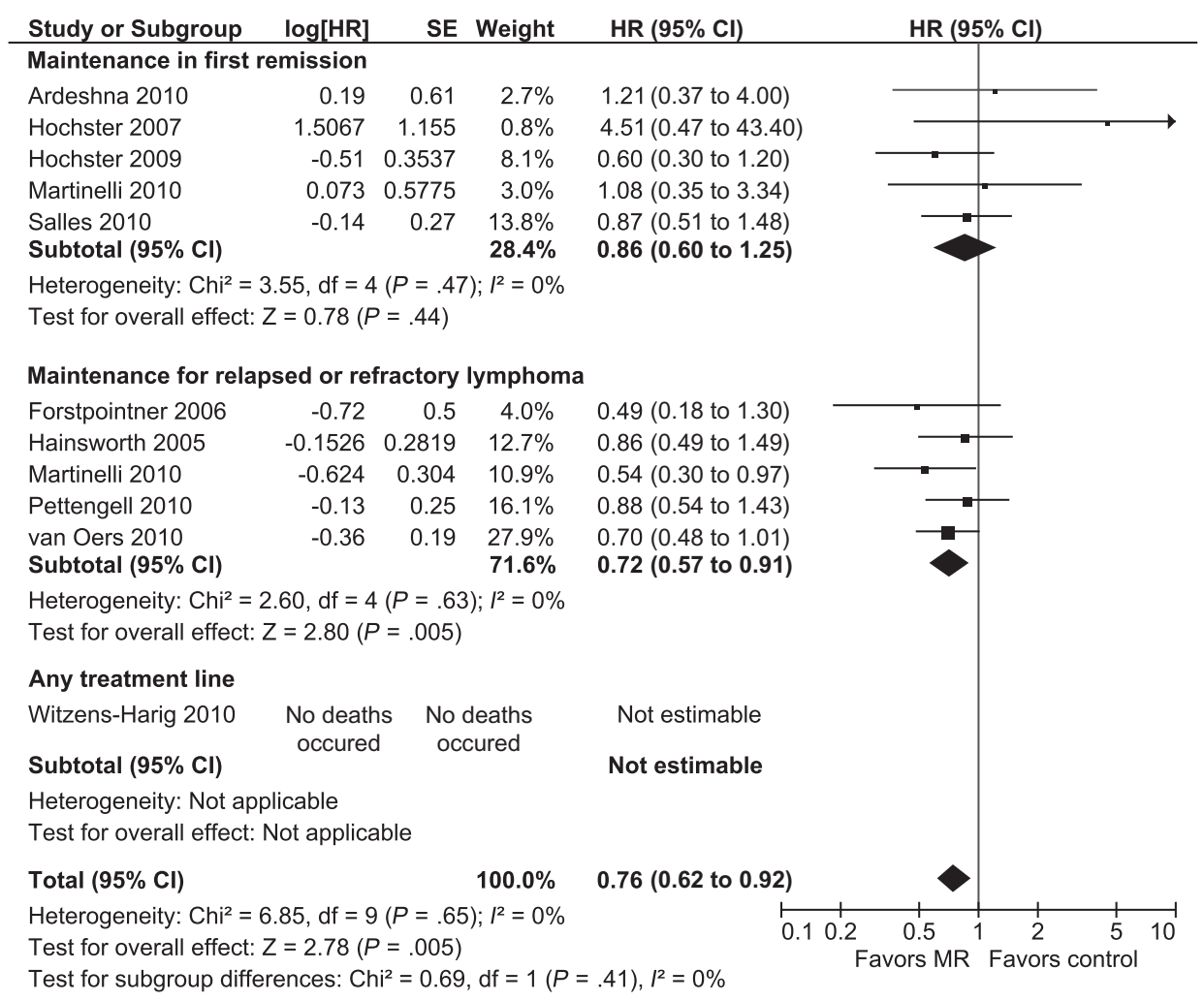

Figure 1. Pooled hazard ratios (HRs) of overall survival of patients with follicular lymphoma after first induction and refractory or relapsed disease. Nine trials were included in meta-analysis; no death occurred in one trial (76), and it did not contribute to the pooled analysis. Black squares represent the point estimate (HR), their sizes represent their weight in the pooled analysis, and the horizontal bars represent the
95\% confidence intervals $(\mathrm{Cls})$, unidirectional arrows represent a limit of the $\mathrm{Cl}$ that is higher than 10 , and the center of the black diamonds represent the pooled point estimate, and their horizontal axis represents the pooled $95 \% \mathrm{Cl}$. The black diamond at the bottom represents the pooled point estimate. $\mathrm{MR}=$ maintenance therapy with rituximab. SE = standard error. this study. Although a clear survival benefit of rituximab maintenance was observed only for patients with relapsed or refractory follicular lymphoma, the magnitude of progression-free survival benefit was similar after first induction as well as after two or more inductions, and was consistent in different subgroups of patients.

A limitation of repeating the metaanalysis is the increased chance of falsepositive results. The reported point estimates and confidence intervals were not adjusted for repeated analyses.

The highly statistically significant progression-free survival benefit of rituximab maintenance was not translated to a statistically significant overall survival benefit after first induction treatment in patients with follicular lymphoma. This may be because a longer follow-up is required to demonstrate a statistically significant difference in survival of patients in first remission whose estimated survival is in the range of decades $(1,80)$, as opposed to few years in patients in second or third remission. Alternatively, disease progression per se may not always be a clinically meaningful event, and second-line treatment may be efficient in these patients. Thus, for patients with relapsed follicular lymphoma who responded to induction therapy, rituximab maintenance should be considered the standard of care. For firstline, treatment options should be discussed with patients in light of the statistically significant prolongation of progressionfree survival vs increased rate of infections.

\section{References}

1. Swenson WT, Wooldridge JE, Lynch CF, Forman-Hoffman VL, Chrischilles E, Link BK. Improved survival of follicular lymphoma patients in the United States. 7 Clin Oncol. 2005;23(22):5019-5026.

2. Carbone PP, Kaplan HS, Musshoff K, Smithers DW, Tubiana M. Report of the Committee on Hodgkin's Disease Staging Classification. Cancer Res. 1971;31(11): 1860-1861.

3. Brice P, Bastion Y, Lepage E, et al. Comparison in low-tumor-burden follicular lymphomas between an initial no-treatment policy, prednimustine, or interferon alfa: a randomized study from the Groupe d'Etude des Lymphomes Folliculaires. Groupe d'Etude des Lymphomes de l'Adulte. 7 Clin Oncol. 1997;15(3):1110-1117.

4. Horning SJ. Natural history of and therapy for the indolent non-Hodgkin's lymphomas. Semin Oncol. 1993;20(5)(suppl 5):75-88.

5. Bachy E, Brice P, Delarue R, et al. Long-term follow-up of patients with newly diagnosed follicular lymphoma in the prerituximab era: effect of response quality on survival-A study from the groupe d'etude des lymphomes de l'adulte. 7 Clin Oncol. 2010;28(5):822-829.

6. Schulz H, Bohlius J, Skoetz N, et al. Chemotherapy plus rituximab versus chemotherapy alone for B-cell non-Hodgkin's lymphoma. Cochrane Database Syst Rev. 2007; 4:CD003805.

7. Conconi A, Motta M, Bertoni F, et al. Patterns of survival of follicular lymphomas at a single institution through three decades. Leuk Lymphoma. 2010;51(6):1028-1034.

8. Salles G, Seymour JF, Offner F, et al. Rituximab maintenance for 2 years in patients with high tumour burden follicular lymphoma responding to rituximab plus chemotherapy (PRIMA): a phase 3, randomised controlled trial. Lancet. 2011;377(9759):42-51. 
9. Ghielmini M, Schmitz SF, Cogliatti SB, et al. Prolonged treatment with rituximab in patients with follicular lymphoma significantly increases event-free survival and response duration compared with the standard weekly $\times 4$ schedule. Blood. 2004;103(12):4416-4423.

10. Forstpointner R, Unterhalt $M$, Dreyling $M$, et al. Maintenance therapy with rituximab leads to a significant prolongation of response duration after salvage therapy with a combination of rituximab, fludarabine, cyclophosphamide, and mitoxantrone (R-FCM) in patients with recurring and refractory follicular and mantle cell lymphomas: results of a prospective randomized study of the German Low Grade Lymphoma Study Group (GLSG). Blood. 2006;108(13):4003-4008.

11. Vidal L, Gafter-Gvili A, Leibovici L, et al. Rituximab maintenance for the treatment of patients with follicular lymphoma: systematic review and meta-analysis of randomized trials. 7 Natl Cancer Inst. 2009;101(4):248-255.

12. Higgins JPT, Green S, eds. Cochrane Handbook for Systematic Reviews of Interventions Version 5.1.0. The Cochrane Collaboration; 2011. www.cochrane-handbook.org.

13. Cheson BD, Pfistner B, Juweid ME, et al. Revised response criteria for malignant lymphoma. 7 Clin Oncol. 2007;25(5):579-586.

14. Parmar MK, Torri V, Stewart L. Extracting summary statistics to perform meta-analyses of the published literature for survival endpoints. Stat Med. 1998;17(24):2815-2834.

15. Tierney JF, Stewart LA, Ghersi D, Burdett S, Sydes MR. Practical methods for incorporating summary time-to-event data into metaanalysis. Trials. 2007;8:16. http://www. trialsjournal.com/content/8/1/16

16. Mantel N, Haenszel W. Statistical aspects of the analysis of data from retrospective studies of disease. 7 Natl Cancer Inst. 1959;22(4): 719-748.

17. DerSimonian R, Laird N. Meta-analysis in clinical trials. Control Clin Trials. 1986;7(3): 177-188.

18. Higgins JP, Thompson SG. Quantifying heterogeneity in a meta-analysis. Stat Med. 2002; 21(11):1539-1558.

19. Baltasar S, Tripp F, Baez E, et al. CNOP vs. CNOP-rituximab vs. rituximab alone as firstline therapy for indolent non-Hodgkin lymphoma (INHL): preliminary results. Blood. 2003;102(11). Abstract 4941.

20. Cheung MC, Haynes AE, Meyer RM, Stevens A, Imrie KR. Rituximab in lymphoma: a systematic review and consensus practice guideline from Cancer Care Ontario. Cancer Treat Rev. 2007;33(2):161-176.

21. Coiffier B. Rituximab in combination with CHOP improves survival in elderly patients with aggressive non-Hodgkin's lymphoma. Semin Oncol. 2002;29(2)(suppl 6):18-22.

22. Fisher RI. Overview of Southwest Oncology Group Clinical Trials in non-Hodgkin Lymphoma. S0016. A phase III trial of CHOP vs CHOP + rituximab vs CHOP + iodine131labeled monoclonal anti-B1 antibody (tositumomab) for treatment of newly diagnosed follicular NHL. Clin Adv Hematol Oncol. 2005; 3(7):544-546.

23. Forstpointner R, Dreyling M, Repp R, et al. The addition of rituximab to a combination of fludarabine, cyclophosphamide, mitoxantrone (FCM) significantly increases the response rate and prolongs survival as compared with FCM alone in patients with relapsed and refractory follicular and mantle cell lymphomas: results of a prospective randomized study of the German Low-Grade Lymphoma Study Group. Blood. 2004;104(10): 3064-3071.

24. Ghielmini M. Adding rituximab to cyclophosphamide, vincristine and prednisone increases time to treatment failure or progression in people with untreated stage III/IV follicular lymphoma. Cancer Treat Rev. 2005;31(8): 644-647.

25. Ghielmini M. Patient benefits of maintenance immunotherapy. Leuk Res. 2006;30(suppl 1): S22-S26.

26. Herold M, Dolken G, Fiedler F, et al. Randomized phase III study for the treatment of advanced indolent non-Hodgkin's lymphomas (NHL) and mantle cell lymphoma: chemotherapy versus chemotherapy plus rituximab. Ann Hematol. 2003;82(2): 77-79.

27. Herold M, Haas A, Srock S, et al. Rituximab added to first-line mitoxantrone, chlorambucil, and prednisolone chemotherapy followed by interferon maintenance prolongs survival in patients with advanced follicular lymphoma: an East German Study Group Hematology and Oncology Study. 7 Clin Oncol. 2007;25(15):1986-1992.

28. Hiddemann W, Dreyling M, Unterhalt $M$. Rituximab plus chemotherapy in follicular and mantle cell lymphomas. Semin Oncol. 2003; 30(1)(suppl 2):16-20.

29. Hiddemann W. Rituximab maintenance therapy in follicular lymphoma comes of age. Leuk Res. 2006;30(suppl 1):S1-S2.

30. Kaplan LD, Lee JY, Ambinder RF, et al. Rituximab does not improve clinical outcome in a randomized phase 3 trial of CHOP with or without rituximab in patients with HIVassociated non-Hodgkin lymphoma: AIDSMalignancies Consortium Trial 010. Blood. 2005;106(5):1538-1543.

31. Kober T, Hulsewede H, Bohlius J, Engert A. Fourth biannual report of the Cochrane Haematological Malignancies Group. 7 Natl Cancer Inst. 2006;98(8):E1.

32. Leppä S, Linna M, Nyman H, Taimela E. Cost-effectiveness of rituximab maintenance treatment versus autologous stem cell transplantation (ASCT) in patients with relapsed follicular lymphoma (FL). Blood. 2006;108(11). Abstract 3337.

33. Marcus R, Imrie K, Belch A, et al. CVP chemotherapy plus rituximab compared with CVP as first-line treatment for advanced follicular lymphoma. Blood. 2005;105(4): 1417-1423.

34. McLaughlin P, Hagemeister FB, Rodriguez MA, et al. Safety of fludarabine, mitoxantrone, and dexamethasone combined with rituximab in the treatment of stage IV indolent lymphoma. Semin Oncol. 2000;27(6)(suppl 12): $37-41$.

35. Rituxan delays disease progression in indolent non-Hodgkin's lymphoma. Oncology (Williston Park). 2002;16(11):1472.

36. Rituximab maintenance stretches progression-free survival in patients with indolent NHL. Oncology (Williston Park). 2004;18(10): 1316.

37. [Milestone in healing fatal indolent lymphoma]. Krankenpfl F. 2004;42(3-4):106-107.

38. Ogura M, Morishima Y, Kagami Y, et al. Randomized phase II study of concurrent and sequential rituximab and $\mathrm{CHOP}$ chemotherapy in untreated indolent B-cell lymphoma. Cancer Sci. 2006;97(4):305-312.

39. Sarris AH, Jiang Y, Tsimberidou AM, et al. Quantitative real-time polymerase chain reaction for monitoring minimal residual disease in patients with advanced indolent lymphomas treated with rituximab, fludarabine, mitoxantrone, and dexamethasone. Semin Oncol. 2002;29(1)(suppl 2):48-55.

40. Solal-Celigny P. Safety of rituximab maintenance therapy in follicular lymphomas. Leuk Res. 2006;30(suppl 1):S16-S21.

41. Rubio-Martinez A, Recasens V, Giraldo P. Maintenance treatment with rituximab in follicular NHL. Blood. 2006;108(11). Abstract 4702.

42. Tomas J, Montalban C, Martinez-Lopez J, et al. Induction with fludarabine, cyclophosphamide and rituximab followed by maintenance with rituximab: results of a prospective study in 75 patients (LNHF-03). Blood. 2006;108(11). Abstract 2762.

43. Witzens-Harig M, Hensel M, Neben K, et al. Rituximab maintenenance therapy in CD20+ B-Cell non-Hodgkin-lymphoma-first interim results of a prospective randomised phase II study. Blood. 2005;106(11). Abstract 2454.

44. Witzens-Harig M, Hensel M, Schmier J, et al. Rituximab maintenenance therapy in CD20+ B-cell non-Hodgkin lymphoma-Interim results of a multicenter prospective randomised phase II study. 7 Clin Oncol. 2006;24(18S):17524. ASCO Annual Meeting Proceedings Part I.

45. Witzens-Harig M, Hensel M, Schmier J, et al. Rituximab maintenenance therapy in CD20+ B-Cell non-Hodgkin-lymphoma-results of a multicenter prospective randomised phase II study. In: 10th Congress of the European Hematology Association. Stockholm, Sweden; 2005.

46. Witzens-Harig M, Hensel M, Schmier J, et al. Rituximab maintenenance therapy in CD20+ B-Cell non-Hodgkin-lymphoma - results of a multicenter prospective randomised phase II study. Blood. 2006;108(11). Abstract 4704.

47. Ghielmini M, Rufibach K, Salles G, et al. Single agent rituximab in patients with follicular or mantle cell lymphoma: clinical and biological factors that are predictive of response and event-free survival as well as the effect of rituximab on the immune system: a study of the Swiss Group for Clinical Cancer 
Research (SAKK). Ann Oncol. 2005;16(10): 1675-1682.

48. Hochster H, Weller E, Ryan T, Habermann TM, et al. Results of E1496: a phase III trial of CVP with or without maintenance rituximab in advanced indolent lymphoma (NHL). Fournal of Clinical Oncology. 2004 ASCO Annual Meeting Proceedings (Post-Meeting Edition). 2004;22(14S) (15 Supplement). Abstract 6502.

49. Van Oers MH, Hagenbeek A, Van Glabbeke M, Teodorovic I. Chimeric anti-CD20 monoclonal antibody (Mabthera) in remission induction and maintenance treatment of relapsed follicular non-Hodgkin's lymphoma: a phase III randomized clinical trial-Intergroup Collaborative Study. Ann Hematol. 2002; 81(10):553-557.

50. Williams M. ECOG 4402: randomized phase III-trial comparing two different rituximab dosing regimens for patients with low tumor burden indolent non-Hodgkin's lymphoma. Curr Hematol Rep. 2004;3(6):395-396.

51. Delaloye AB, Antonescu C, Louton $\mathrm{T}$, Kuhlmann J, Hagenbeek A. Dosimetry of 90Y-ibritumomab tiuxetan as consolidation of first remission in advanced-stage follicular lymphoma: results from the international phase 3 first-line indolent trial. $7 \mathrm{Nucl} \mathrm{Med}$. 2009;50(11):1837-1843

52. Hainsworth JD, Spigel DR, Markus TM, et al. Rituximab plus short-duration chemotherapy followed by Yttrium-90 Ibritumomab tiuxetan as first-line treatment for patients with follicular non-Hodgkin lymphoma: a phase II trial of the Sarah Cannon Oncology Research Consortium. Clin Lymphoma Myeloma. 2009;9(3):223-228.

53. Hayslip JW, Simpson KN. Cost-effectiveness of extended adjuvant rituximab for US patients aged 65-70 years with follicular lymphoma in second remission. Clin Lymphoma Myeloma. 2008;8(3):166-170.

54. Hensel M, Witzens-Harig M, Dreger P, Ho $\mathrm{AD}$, Thurley D, Oertel S. A phase IIIb study of rituximab maintenance therapy in patients with follicular non-Hodgkins lymphoma who have responded to induction therapy-MAXIMAprotocol. Blood. 2006;108(11):Abstract 4706.

55. Hicks LK, Woods A, Buckstein R, et al. Rituximab purging and maintenance combined with auto-SCT: long-term molecular remissions and prolonged hypogammaglobulinemia in relapsed follicular lymphoma. Bone Marrow Transplant. 2009;43(9):701-708.

56. Hitz F, Bassi S, Taverna C, et al. First results of long term rituximab maintenance treatment in follicular lymphoma: safety analysis of the randomized phase III trial SAKK 35/03. Haematologica. 2009;94(suppl 2):167-168. Abstract 0413

57. Jacobs SA, Swerdlow SH, Kant J, et al. Phase II trial of short-course CHOP-R followed by 90Y-ibritumomab tiuxetan and extended rituximab in previously untreated follicular lymphoma. Clin Cancer Res. 2008;14(21): 7088-7094.

58. Johnston A, Bouafia-Sauvy F, BroussaisGuillaumot F, et al. Retreatment with rituximab in 178 patients with relapsed and refractory B-cell lymphomas: a single institution case control study. Leuk Lymphoma. 2010;51(3):399-405.

59. Kasteng F, Erlanson M, Hagberg H, Kimby E, Relander T, Lundkvist J. Cost-effectiveness of maintenance rituximab treatment after second line therapy in patients with follicular lymphoma in Sweden. Acta Oncol. 2008;47(6): 1029-1036.

60. Kimby E, Jurlander J, Geisler C, et al. Longterm molecular remissions in patients with indolent lymphoma treated with rituximab as a single agent or in combination with interferon alpha-2a: a randomized phase II study from the Nordic Lymphoma Group. Leuk Lymphoma. 2008;49(1):102-112.

61. Luminari S, Marcheselli L, Sacchi S, et al. Anthracycline-fludarabine-containing regimens with or without rituximab in the treatment of patients with advanced follicular lymphoma. Cancer. 2009;115(9):1906-1913.

62. Marcus R, Aultman R, Jost F. A qualityadjusted survival analysis (Q-TWiST) of rituximab plus CVP vs CVP alone in first-line treatment of advanced follicular non-Hodgkin's lymphoma. Br 7 Cancer. 2010;102(1):19-22.

63. McClanahan F, Hielscher T, Rieger M, et al. Clinical outcome of patients with follicular lymphoma and bulky disease after RituximabCHOP immunochemotherapy with and without consolidating radiotherapy. Eur $\mathcal{f}$ Haematol 2010;85(1):11-19.

64. Ray JA, Carr E, Lewis G, Marcus R. An evaluation of the cost-effectiveness of rituximab in combination with chemotherapy for the firstline treatment of follicular non-Hodgkin's lymphoma in the UK. Value Health 2010; 13(4):346-357.

65. Salles G, Mounier N, de Guibert S, et al. Rituximab combined with chemotherapy and interferon in follicular lymphoma patients: results of the GELA-GOELAMS FL2000 study. Blood. 2008;112(13):4824-4831.

66. Sebban C, Brice P, Delarue R, et al. Impact of rituximab and/or high-dose therapy with autotransplant at time of relapse in patients with follicular lymphoma: a GELA study. 7 Clin Oncol. 2008;26(21):3614-3620.

67. Tobinai K, Watanabe T, Ogura M, et al. Japanese phase II study of 90Y-ibritumomab tiuxetan in patients with relapsed or refractory indolent B-cell lymphoma. Cancer Sci. 2009;100 (1):158-164

68. Wenger MK, Foa R, Arcaini L, et al. The MAXIMA study: safety of rituximab (MabThera®) maintenance therapy in patients with follicular non-Hodgkins lymphoma who have responded to induction therapy. Blood. 2007;110(11):189b-190b. Abstract 4475.

69. Ardeshna KM, Qian W, Smith P, et al. An intergroup randomised trial of rituximab versus a watch and wait strategy in patients with stage II, III, IV, asymptomatic, non-bulky follicular lymphoma (grades 1, 2 and 3a). A preliminary analysis. Blood. 2010(21);116. Abstract 6 (ASH Annual Meeting Abstracts).

70. Hainsworth JD, Litchy S, Shaffer DW, Lackey VL, Grimaldi M, Greco FA.
Maximizing therapeutic benefit of rituximab: maintenance therapy versus re-treatment at progression in patients with indolent nonHodgkin's lymphoma — a randomized phase II trial of the Minnie Pearl Cancer Research Network. 7 Clin Oncol. 2005;23(6):1088-1095.

71. Hochster H, Weller E, Gascoyne RD, et al. Maintenance rituximab after cyclophosphamide, vincristine, and prednisone prolongs progression-free survival in advanced indolent lymphoma: results of the randomized phase III ECOG1496 Study. 7 Clin Oncol. 2009; 27(10):1607-1614.

72. Martinelli G, Schmitz SF, Utiger U, et al. Long-term follow-up of patients with follicular lymphoma receiving single-agent rituximab at two different schedules in trial SAKK 35/98. 7 Clin Oncol. 2010;28(29):4480-4484.

73. Pettengell R, Schmitz N, Gisselbrecht C, et al. Randomized study of rituximab in patients with relapsed or resistant follicular lymphoma prior to high-dose therapy as in vivo purging and to maintain remission following highdose therapy. 7 Clin Oncol. 2010;28(suppl):7s. Abstract 8005

74. van Oers MH, Klasa R, Marcus RE, et al. Rituximab maintenance improves clinical outcome of relapsed/resistant follicular nonHodgkin lymphoma in patients both with and without rituximab during induction: results of a prospective randomized phase 3 intergroup trial. Blood. 2006;108(10):3295-3301.

75. van Oers $M H$, Van Glabbeke M, Giurgea L, et al. Rituximab maintenance treatment of relapsed/resistant follicular non-Hodgkin's lymphoma: long-term outcome of the EORTC 20981 phase III randomized intergroup study. 7 Clin Oncol. 2010;28(17):2853-2858.

76. Witzens-Harig M, Benner A, Rieger M, et al. Rituximab maintenenance therapy in CD20+ B-Cell non-Hodgkin-lymphoma-final results of a multicenter prospective randomised phase II study. Blood. 2009;114(22):1707. (ASH Annual Meeting Abstracts).

77. Witzens-Harig M, Reiz M, Heiss C, et al. Quality of life during maintenance therapy with the anti-CD20 antibody rituximab in patients with B cell non-Hodgkin's lymphoma: results of a prospective randomized controlled trial. Ann Hematol. 2009;88(1):51-57.

78. Vitolo U, Ladetto M, Boccomini C, Gamba E, Alvarez I, Baldini L. Brief chemoimmunotherapy rituximab (R)-FND +/- $\mathrm{R}$ maintenance is effective and safe in newly diagnosed follicular lymhpoma elderly patients: an intergruppo italiano linfomi (IIL) randomized trial. Haematologica. 2009;94(suppl 2):417-418.

79. Hochster H, Weller E, Gascoyne R, et al. Cyclophosphamide and fludarabine (CF) in advanced indolent lymphoma: results from the ECOG/CALGB intergroup E1496 trial. 7 Clin Oncol. 2007;25(18S):8004. ASCO Annual Meeting Proceedings Part I.

80. Pulte D, Gondos A, Brenner H. Ongoing improvement in outcomes for patients diagnosed as having non-Hodgkin lymphoma from the 1990 s to the early 21 st century. Arch Intern Med. 2008;168(5):469-476. 


\section{Funding}

This research was supported by F. HoffmannLa Roche Ltd, Basel (an unrestricted grant to O.S., grant number Km209450133).

\section{Notes}

The authors are solely responsible for the study design, data collection, analysis and interpretation of the data, writing the article, and decision to submit the article for publication. Roche (manufacturer of rituximab) had no involvement in any of these activities or in any part of the study conduction. Drs Dreyling, Salles, and Shpilberg received honoraria from Roche.

Affiliations of authors: Institute of Hematology, Davidoff Cancer Center, Rabin Medical Center, Petah-Tikva, Israel (LV, AG-G, OS); Sackler School of Medicine, Tel Aviv University, Tel Aviv, Israel (LV, AG-G, OS); Hospices Civils de Lyon and Université de Lyon, Pierre-Benite, France (GS); Department of Internal Medicine
III, University Hospital Munich, Campus Grosshadern, Munich, Germany (MHD); Department of Medical Oncology, Oncology Institute of Southern Switzerland, Bellinzona, Switzerland (MG); Swiss Group for Clinical Cancer Research, Bern, Switzerland (SH); Department of Haematology, St. George's University of London, London, UK (RP); Department of Hematology and Oncology, University Hospital of Heidelberg, Heidelberg, Germany (MW-H). 